\title{
CORRESPONDENCE.
}

\section{ON THE SETTLEMENT OF LOSSES BY FIRE UNDER AVERAGE POLICIES.}

\section{To the Editor of the Assurance Magazine.}

Sin,-I have read with great attention the article "On the Settlement of Losses by Fire under Average Policies," which appeared in the Assurance Magazine of October last, and am very glad that the complications and difficulties likely to arise from the hasty alteration of the common average clause have been so ably set forth by Mr. Atkins.

It is evident that the introduction of the "independent liability" clause has been made without due thought, and without proper regard to the interests of certainly one of the most interested parties concerned in all assurance contracts-namely, the assured.

Take, for instance, the example given in Mr. Atkins' paper at page 9, where the case he supposes is this-

$$
\begin{aligned}
& \text { Office A, } £ 5,000 \text { docks . . . . . . . } \begin{array}{c}
\text { Property. } \\
£ 5,000 \text { doeks. }
\end{array}
\end{aligned}
$$

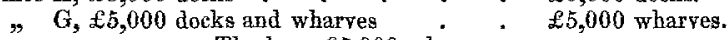

$$
\begin{aligned}
& \text { The loss, } \mathfrak{E} 5,000 \text { wharyes. }
\end{aligned}
$$

In this case, if the "independent liability" clause be acted upon in the settlement of this loss, according to the letter, in its plain and obvious meaning, and in its strict integrity, the assured, although fully covered "as far as the total amount of insurance was concerned," wonld only recover half his loss. Office A not being interested in the wharves, the loss would fall entirely nopon Office $G$, and would stand thus-

$\begin{array}{cccc}\text { Amount of Goods } & \text { Office } G & & \text { Loss. } \\ \text { at time of Fire. } & \text { Policy. } \\ £ 10,000 & : & £ 5,000 \quad: & £ 5,000=£ 2,500 .\end{array}$

It is all very well for Mr. Atkins to argne that the Offices must agree to consider and treat policies having a lesser range of average as specified policies, and allow the amounts thereof to be deducted from the amount of goods at time of the fire; vut this is clearly not the plain literal meaning of the "independent liability" clanse; and the settlement of any loss (under policies containing this clause) in the manner proposed by Mr. Atkins, while it remains unaltered, would, in fact, be saying one thing and doing another, and thereby placing the assured in a false position with the Offices-a position to which the mercantile community will not be likely to submit when the prineiple becomes comprehended.

The settlement of a loss under varions policies containing this clause, will, doubtless, be more just and equitable between Office and Office when all the policies include the place at which the loss may have occurred; but, as between the Offices and the assured, something must assuredly be done to remedy the defect pointed out, before another dock or wharf fire occurs.

A clanse shonld be added to the conditions of average, to the effect that policies of a lesser range will be considered as specific assarances when they do not inclnde the place where the loss may have happened, if the practice 
suggested by Mr. Atkins is to be adopted; and then "the settlement of losses by fire under arerage policies" would be in conformity with the conditions, and not in opposition to them.

I am, Sir,

Your obedient servant,

Atlas Fire Offee,
17th November, 1858.

R. RAY.

\section{ON CERTAIN ADVANTAGES AFFORDED BY MR. CHISHOLM'S TABLES RECENTLY PUBLISHED.}

\section{To the Editor of the Assurance Magazine.}

Sir, - In the last Number of the Assurance Magazine, your able correspondent, Mr. T. B. Sprague, has given a formula, adapted to the $\mathrm{D}$ and $\mathrm{N}$ columns, for obtaining the annual premium for a term assurance on two joint lives, under the impression that Mr. David Jones, in his treatise on annnities, had overlooked it. He has evidently not observed, that, in the edition of Mr. Jones's valnable work, published nnder the superintendence of the "Society for the Diffusion of Useful Knowledge," a list of formula is prefixed to the second volume, ermtaining, amongst others, the formula, the supposed want of which excites Mr. Sprague's surprise.

It is as follows-

$$
P_{m, n_{3}, 7}=r-\frac{\mathrm{N}_{m, m_{1}}-\mathrm{N}_{m+m, m_{\mathrm{I}}+n}}{\mathrm{~N}_{m-1, m_{1}-1}-\mathrm{N}_{m+n-1, m_{1}+n-1}},
$$

and coincides with that given by $\mathrm{Mr}$. Sprague.

Perhaps it may not be out of place here, to allude to the facilities now afforded for the solution of this and cognate problems by the valuable contribution recently made by $\mathrm{Mr}$. David Chisholm to the seience of Life Assurance. The $\mathrm{M}$ and $\mathrm{R}$ columns, as calculated by him, representing the contingency of survivorship, have effected a most material simplification in the methods formerly employed for finding values in which this contingency is involved, and have snpplied a want which was most urgently felt. Indeed, by $\mathrm{Mr}$. Chisholm's arduous labonrs, the commutation system, originated by Mr. Barrett, improved by Mr. Davies, and extended and illustrated by Mr. Jones, has been rendered complete in so far as relates to one and two lives.

But to return to the question alluded to at the commencement of this letter : the columns $M_{\frac{1}{x} y}$ and $M_{\frac{x}{x}, y}^{1}$, as tabulated by $\mathrm{Mr}$. Chisholm, being complementary, may be used for the solution of questions connected with joint life assurances; and as these converse values are placed on opposite pages, the facility of using them is greatly increased. The formula for the anual premium for a term joint assurance is just an extension of that for single lives, being

$$
\frac{M_{x, y}^{1}+M_{x, y}^{1}-M_{x+n, y+n}+M_{x+n y+n}}{N_{x \cdot y}-N_{x+n \cdot y+n}} .
$$

The expression for the annual preminm for an assurance deferred $n$ years is 